\title{
Investigating the Awareness and Usage of Moodle Features at Hashemite University
}

\author{
Haneen Hijazi ${ }^{1}$, Ghadeer Al-Kateb ${ }^{2}$ \\ Faculty of Information Technology \\ Hashemite University \\ Zarqa, Jordan
}

\author{
Eslam Alkhawaldeh ${ }^{3}$ \\ Department of e-learning \\ Hashemite University \\ Zarqa, Jordan
}

\begin{abstract}
E-learning plays a vital role in the educational process. Learning management systems are being essential component of e-learning. Moodle learning management system is being widely used in Higher Education Institutions due to the rich features it provides that support the learning process. Standard Moodle comprises 21 features (14 activities and 7 resources). Little research has been carried out to examine these features in particular. In this research, the awareness and usage of Moodle features among faculty members at Hashemite University, Jordan are investigated. A sample of 140 instructors were surveyed. Then, the responses were analyzed to find the overall awareness and usage of each feature. Furthermore, the correlation between awareness and usage and how the awareness of Moodle features is associated with their usage were analyzed through correlation and regression analysis. The study revealed that instructors expressed highest awareness towards File, Folder, Assignment, URL and Quiz features whilst the least awareness was towards SCORM package and IMS content package features. Regarding usage, the study identified the File, Folder, Assignment and URL features as the most heavily used features whereas the least commonly used features have been IMS Content Package, SCORM package, Wiki, Glossary, Workshop, Database, Survey, External tool and Choice. Moreover, the study statistically demonstrated a strong correlation between the awareness and usage of features and that changes in the awareness of Moodle features are significantly associated with changes in their usage. In other words, the study revealed that features with low awareness tend to have low usage and that the usage would increase as the awareness increases. The study would help Moodle administrators in Higher Education Institutions decide about the most important features that should be installed in their customized instance of Moodle. Furthermore, the study would help Hashemite University responsible parties in identifying the least commonly used and the least well-known features, allowing them to focus on increasing the levels of awareness and usage of those features in a way that might reflect positively on the learning process.
\end{abstract}

Keywords-Moodle; learning management system; features; awareness; usage; activities; resources; tools; correlation; regression

\section{INTRODUCTION}

E-learning is being involved considerably in higher education. It is about the use of Information and Communications Technology (ICT) in delivering education either fully online or partially (i.e. blended learning). In either form, two major components constitute the infrastructure of any e-course. These components are the e-content and the Learning Management System (LMS).

A learning management system is a virtual learning environment that allows communication between students and instructors, and between the students themselves. The instructor through the LMS can upload material, assignments, quizzes and answer questions, while students can read material, ask questions, communicate with each other and do assignments and quizzes. All these activities are performed online using the features that are embedded in the LMS.

Moodle is a "learning platform designed to provide educators, administrators and learners with a single robust, secure and integrated system to create personalized learning environments" [1]. "Moodle" stands for "Modular ObjectOriented Dynamic Learning Environment" [2]. It is an opensource LMS, hence, its use to support the learning process is popular in HEIs all over the world. An administrator can download it for free, customize it, and participate in several public forums to discuss Moodle issues.

Latest version of Moodle (3.8) was released in Nov 2019 [3]. Standard Moodle offers several learning features. The feature that a student uses [4] to interact with other students and/or the teacher is called "Activity". In contrast, the feature that is presented by the teacher [4] to the students in purpose of supporting learning is called "Resource".

According to [5], standard Moodle encompasses 14 different types of activities, these activities are: "Assignment" activity; which allows students to do the created assignment online and allows instructors to grade and give feedback. "Chat" activity; that allows participants to communicate synchronously. "Choice" activity to allow students to answer a multiple-choice question. "Database" activity; which allows participants to create, maintain and search a set of record entries. "Feedback" activity; that allows instructors to create custom surveys through a variety types of questions to collect feedback from students. "Forum" activity; allows participants to communicate asynchronously. "Glossary" activity; that enables participants to create and maintain a list of definitions. "Lesson" activity; to enable instructors to design and deliver instructional content. "(LTI) External tool”; enables students to interact with learning resources and activities on other web sites. "Quiz" activity; which enables instructor to design a test comprising questions of various types, grade it automatically or manually, and give feedback. A "SCORM" activity that is used 
to present multimedia content and to assess students according to an agreed standard for learning object. "Survey" activity allows instructors to assess their courses through several verified survey instruments. "Wiki" activity; enables participant to create and edit a collection of web pages which can be either collaborative or individual. And lastly, a "Workshop" activity the enables peer assessment of students' work.

Also, as per [6], standard Moodle provides 7 types of resources: "Book" resource; that is a multi-page resource in a book-like format. "File" resource; which is used to display images, documents, spreadsheets, presentations, sound files and videos. A "Folder" resource to organize files. "IMS content package" resource; that is used to add material from other sources as a collection of files packaged according to an agreed standard. "Label" resource which uses text and multimedia to separate course elements or to give descriptive information and instructions. "Page" resource; that is used to create a web page using the text editor or html editor, such pages may display text, media files, web links and embedded code, such as Google maps. Finally, a "URL" resource to provide a web link for a resource that is available outside.

In Jordan, almost all public universities are using Moodle as a LMS platform. Hashemite University (HU) is a public university in Jordan that was established in 1995. It has 15 faculties: Tourism and Heritage, Science, Applied Health Sciences, Nursing, Arts, Physical Education and Sport Science, Information Technology, Engineering, Medicine, Pharmaceutical Sciences, Economics and Administrative Science, Educational Sciences, Childhood, Natural Resources and Environment, and Arid Lands in addition to the Graduate Studies faculty.

HU adopted e-learning to support the educational process early. HU payed valued efforts to capitalize and employ elearning technologies in the learning process [7]. As well, HU is one of the universities of Jordan that employed LMS in the learning process very early. In the early beginning, HU used Blackboard then, in the early 2012 [8], HU migrated to Moodle for being open-source and many other issues. The current version of Moodle that is installed at HU is 3.1.1. HU Moodle hosts over 1500 course. Most courses are traditional face to face courses that uses LMS and e-content to support the learning process while a few courses are being delivered online. In both forms, LMS plays a vital role in the learning process.

In HU, Moodle is configured so that students are enrolled automatically when they register for a course. This customized version of $\mathrm{HU}$ includes all features that are available in the standard Moodle. The usage of Moodle features depends on several factors; it depends on its usefulness and usability and how lecturers perceive them [4]. The choice and usage of a certain feature depend on its impact on the lecturer workload and how much time it saves [9] [10]. Moreover, feature usage depends the available equipment, Internet connection and the availability of other tools and features [10].

Principally, this research investigates the awareness and usage of Moodle features among HU faculty. The awareness could be described as the degree of perception that the instructors have towards each Moodle feature and its specific use. The most well-known features and the least well-known will be highlighted (RQ1). On the other hand, the usage describes how frequent each feature is used by instructors. The most commonly used features and the least commonly used ones will also be emphasized (RQ2). Theoretically, it is believed that the awareness of Moodle features is associated with their usage. Features with low awareness is expected to have low usage and this usage would increase as the awareness increases. However, this research aims to statistically investigate the relationship between the awareness and usage of Moodle features and how changes in the awareness are associated with changes in the usage (RQ3).

The main research questions are:

- RQ1: Which Moodle features have the highest awareness, and which features have the least awareness among HU faculty?

- RQ2: Which Moodle features are used most frequently, and which features are used least frequently by $\mathrm{HU}$ faculty?

- RQ3: Is there a statistical relationship between faculty's awareness of Moodle features and their usage?

- RQ4: Based on (activities/resources) classification of Moodle features, which category has highest/least awareness and which category is most/least frequently used?

- RQ5: Based on the adopted functional classification of features, which categories have the highest/least awareness and which categories are the most/least frequently used?

The rest of this paper is organized as follows: Section 2 highlights the related work, Section 3 introduces the method, Section 4 presents the results, Section 5 discusses the results and limitations and Section 6 concludes the paper.

\section{RELATED WORK}

The literature is rich of studies that aimed at evaluating Moodle as a learning management system, but very few studies examined its features [4]. The main purposes for using Moodle at Kajaani University of Applied Sciences, Finland were reported by KC [4]. KC also evaluated Moodle features (i.e. activities and resources) that were implemented in the Moodle instance they used. The author conducted an online questionnaire that targeted teaching staff and used qualitative weight and sum (QWS) approach. The customized instance of Moodle in Kajaani University embedded 12 activities: assignment, choice, database, feedback, forum, glossary, lesson, quiz, SCORM package, survey, wiki and workshop, and 6 resources: book, file, folder, label, page and URL. The results show that among all features, assignment, feedback, quiz and workshop modules were considered very essential and were heavily used. A comparison between Moodle and Facebook in delivering learning in LPU-L was conducted in [11]. The authors compared the overall acceptance, accessibility and usage of the common features (i.e. chat, groups, search engines, announcements and 
downloading/uploading files) among both instructors and students. They found that group feature is the most used feature in Facebook, whereas download/upload feature is the most used feature in Moodle. They recommended that Moodle should be improved in order to improve students' perception towards it.

Combined Qualitative Weight and Sum (QWS) and Analytic Hierarchy Process (AHP) approaches were conducted in [12] evaluate and compare 9 open-source LMSs based on 5 criteria, namely, social networking, productivity, administration, presentation, and management. The authors used 35 features classified into subcategories of the adopted 5 criteria. They found that the highest evaluated LMS is Intelligent Web Teacher (IWT), followed by Claroline and in the third place is the Moodle, whilst the most frequently used open source LMS in Jordan universities is Moodle. They claimed that the result of their study would help HEI to choose the proper LMS and to define the most important features to be activated according to students. In [13], Hasan investigated 24 features of Moodle on both desktop and mobile devices from students' perspective in a university in Jordan. She found that among the 24 Moodle features, only 6 features were installed and frequently used by students and 18 other features were required by students but not installed. Moreover, she evaluated the usability of the installed Moodle instance and came out with 17 usability problems. She also proposed 10 improvements according to students to enhance the usability of Moodle.

The use of Moodle tools and functionalities by the University of Aveiro students was analyzed in [14]. The authors used content analysis, structured interview with the Moodle administrator and a questionnaire that targeted the university students. They found, according to the questionnaire, that $98 \%$ of respondents used Moodle to download materials, $84 \%$ to see news, and that Moodle is least commonly used to deliver assignments, communicate with teachers and Ask questions. Teachers' individual information, teachers' frequency of use of Moodle activities (12 activity), and teachers' perception of how the use of Moodle impacts learning in secondary schools in Catalonia (Spain) were investigated [15]. The researchers found that assignment, quiz, forum, lesson and external tools were the most commonly used activities, while workshop, database and Wiki were the least commonly used. In their research, they did not tackle Moodle resources. The researchers in [16] explored satisfaction levels and usage of 8 features (Assignment, news/announcement, gradebook, events, online assessment, calendar and forum) of Moodle LMS for 47 faculty at CHS. Among the 8 features they investigated, assignment was the most commonly used and forum was the least.

A trial to improve student collective work for the "Multimedia for web-based e-learning" track in Trakia University, Stara Zagora, using the improved collaborative features in Moodle like glossary, wiki and forum was presented in [17]. Purbojo [18] collected Moodle logs files, reports, learning outcomes data, and interview data and performed quantitative and qualitative statistical analyses. Purbojo found that several behavioral characteristics exist for the instructor's role in utilizing Moodle features.
Researchers proposed several categories that can be used to classify LMS features based their functionalities. As per [19], LMSs features can be creation, organization, delivery, communication, collaboration and assessment. In [10], the authors adopted a 4-categories classification to group LMS features: distribution, communication, interaction and course administration. Another categorization by Hamtini and Fakhouri [12] involves Social networking, productivity and software installation, administration and security, presentation and material distribution, and management. Based on these categories, several researchers classified Moodle activities, particularly, based on their perceived functionalities. Costa, Alvelos and Teixeira in [14] adapted Piotrowski [19] categories and added the reusability category to classify Moodle features. They classified Moodle activities as follows: creation (database), organization (lessons), delivery (assignments, workshops), communication (chats, forums, news), collaboration (glossary, wikis), assessment (choice, quiz, survey, and feedback) and reusability of learning resources (SCORM, and external tools). Similarly, Badia, Martín, and Gómez in [15] adopted the categorization of Moodle features in [14] except that they did not tackle 3 features (i.e. news, feedback and SCORM). University of Massachusetts at Amherst [20] classified activities available in their Moodle into: assignments (Moodle Assignments, Turnitin Assignment, External Tool), communication and collaboration (chat, database, forum, glossary, wiki, workshop), Assessment and surveys (quiz, questionnaire, choice), management (attendance, checklist, group self-selection), and interactive delivery of content (lesson and SCORM).

Accordingly, the literature lacks such studies that have been concerned with evaluating the awareness and usage of all Moodle features that are available in the standard Moodle installation. Consequently, the relationship between the awareness and usage of Moodle features have never been investigated. Hence, evaluating Moodle features awareness and usage among HU faculty and the relationship between them is the focal goal of this research.

\section{METHOD}

An online survey that targeted HU's instructors was designed and distributed. The survey was developed using Google Forms. It started with the contact information of respondents, then for each Moodle feature two questions were asked:

• Describe your "Awareness" of "feature name"?

- Describe your "Usage" of "feature name"?

For the "awareness" questions, 5 choices were given (i.e. extremely aware, very aware, moderately aware, slightly aware, not at all aware). For the "usage" questions, 5 choices were given (i.e. always, often, sometimes, rarely, never).

As a first step, the researchers communicated with the university administration to ask faculty members to facilitate the process of distributing the survey stating that it is for research purposes. Then the survey was distributed via email among the majority of HU faculty who are currently on their 
work. The survey was conducted in the interval Feb 10th to Apr 7th from the year 2020.

Data were analyzed using IBM SPSS Statistics and Microsoft Excel. Survey items were classified into two groups. One group includes the items that assess the awareness of Moodle features and the other group includes the items that assess the usage of Moodle features.

In order to measure the reliability of the survey items, Cronbach's alpha was used. Cronbach's alpha is used to measure the internal consistency of a scale with a value lies between 0 and 1 [21]. As both the awareness and usage of Moodle features are evaluated in this survey, two Cronbach's alpha values were calculated. The first Cronbach's alpha measures the internal consistency of the first group (i.e. the items that evaluate the awareness). As the internal consistency describes the degree to which all the items in a test measure the same concept [21]; a higher value of alpha for awareness items would indicate that the items actually measure the awareness of the Moodle features. The other alpha is used to measure the internal consistency of the second group (i.e. the items that evaluate the usage). Likewise, a higher value of alpha for usage items would indicate that the items actually measure the usage. Several qualitative descriptors were reported in the literature to interpret the value of alpha, the majority agreed that a value around 0.7 or above is desirable [22].

In order to describe the overall awareness and the overall usage for each Moodle feature, mean value was calculated for each item. To advocate the results, the median and mode were also calculated. For these statistical purposes, a numerical rate between 5 and 1 was given for each response. For the "awareness" questions; extremely aware=5, very aware=4, moderately aware $=3$, slightly aware $=2$, not at all aware $=1$. For the "usage" questions, always $=5$, often $=4$, sometimes $=3$, rarely $=2$, never $=1$. The mean was calculated for each item by finding the summation of the numeric values of all responses, and then dividing by the number of respondents.

The features were ranked according to the overall awareness and usage based on means. Moreover, the median (i.e. the response for which $50 \%$ of responses are higher and $50 \%$ are lower) and the mode (i.e. the most common response) for both awareness and usage were reported.

Calculating Pearson correlation coefficient between two variables requires a linear relationship to be exist between these variables [23]. A scatter plot is considered a good way to check for linearity [23].

Hence, in order to check whether there is a linear relationship between the awareness and usage, a scatterplot was used. Correlation analysis was conducted to investigate the degree to which the two variables (i.e. awareness and usage) are closely related [24].

A correlation coefficient (r) was calculated. Typically, a correlation coefficient value lies between -1 and +1 [25]. A value of 0 implies no correlation. A positive value indicates a positive correlation (i.e. as one variable increases, the other variable increases too). A negative value indicates a negative correlation (i.e. as one variable increases, the other variable decreases). Only correlations that are significant (i.e. with p- value less than the significance level $(\alpha=0.05)$ ) should be considered [25]. Hence, if the test results with p-value less than 0.05 , then this correlation is considered statistically significant at the population level.

For further investigation about how the awareness is associated with usage, simple linear regression test was conducted. The awareness was assumed the independent variable (predictor) and the usage was assumed the dependent variable (response).

The p-value for the for the coefficient of the independent variable (i.e. awareness) is used to assess whether changes in the independent variable are really associated with changes in the dependent variable [26]. A (p-value $<=0.05$ ) for the coefficient of the independent variable (i.e. awareness) means that this relationship is statistically significant. In other words, changes in the independent variable (i.e. awareness) value are related to changes in the dependent variable (i.e. usage) value at the population level.

In order to assess the trustworthy of the regression results [27] and the suitability of this regression model to the dataset, residuals analysis was also conducted.

Moreover, as Moodle features are either activities (14) or resources (7), the overall awareness and the overall usage for the activities and resources were calculated by finding the mean of means for both categories.

Furthermore, the 21 Moodle features implemented in HU installation were classified based on their main functionalities into seven categories. This 7-categories classification is based on [19] [14] [20] with some modifications. The "Content delivery" category includes the simple features that are used to communicate content to students such as file, book and page. "Standardized Content Packages" category includes the features that the instructor can leverage to create multimedia content according to an agreed standard such as SCORM and IMS packages. "External Resources" that provide access to resources outside the Moodle instance like URL and external tool. "Communication" features that allow discussions synchronously such as chat and asynchronously such as forum. "Collaboration features" that enable participants to work together such as database, glossary, wiki and workshop. "Direct Assessment" features that allow instructors to measure how well students have mastered course learning outcomes [28] such as Assignment and Quiz features. "Indirect Assessment" features that are used to gather data from students usually to evaluate their understanding or to evaluate the course based on students' perceptions and satisfaction such as choice, feedback and survey features. Then, the overall awareness and usage for each category were calculated by finding the mean of means.

\section{RESULtS}

A total number of 140 responses were returned. The respondents were from different faculties, namely, Science (22.86\%), Information Technology (18.57\%), Engineering (18.57\%), Arts (and languages center) (10.00\%), Economics and Administrative Sciences (7.14\%), Nursing (6.43\%), Applied Health Sciences (5.71\%), Medicine (3.57\%), Educational Sciences (2.86\%), Natural Resources and 
Environment (2.14\%), Physical Education and Sport Science (0.71\%), Pharmaceutical Sciences $(0.71 \%)$ and Arid Lands (0.71\%). Fig. 1 shows the distribution of participants among different faculties in HU.

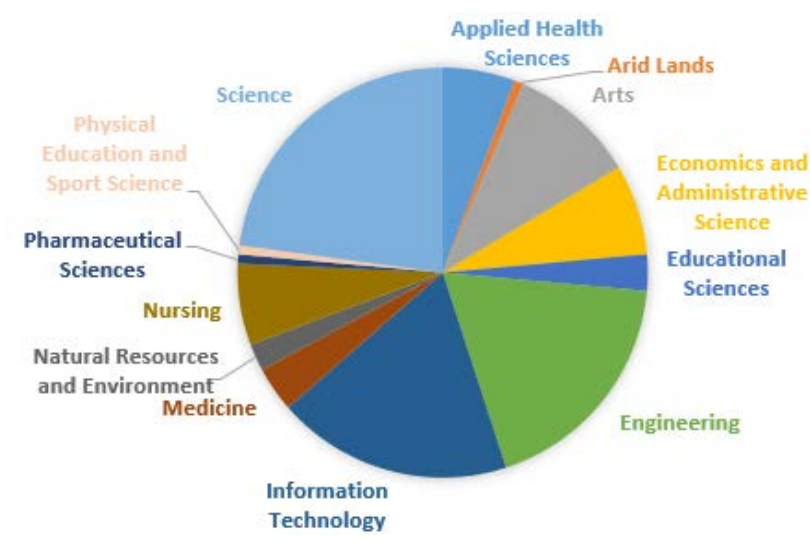

Fig. 1. Respondents Distribution among Faculties.

Reliability tests resulted with a Cronbach's alpha value of 0.94 for the group of items that assess the awareness of Moodle features. This high value implies that the items in this group are internally consistent and actually measures the awareness. Another Cronbach's alpha was calculated to assess the internal consistency among the items that assess the usage. This value of 0.93 implies a high consistency and that the items actually measures the usage.

- RQ1: Which Moodle features have the highest awareness, and which features have the least awareness among $\mathrm{HU}$ faculty?

Features awareness analysis results are displayed in Table I. For each feature, mean, median and mode are displayed. The features in the table were sorted descending according to the mean, which was used to describe the overall awareness. As per the table, HU's instructors exhibited the highest awareness towards the File feature (4.59), followed by Folder (3.85), Assignment (3.62), URL (3.56) and Quiz (3.46). These were the features that had the highest awareness among $\mathrm{HU}$ instructors. This result is also supported by the median and mode values as displayed in the table. The least awareness was towards SCORM package (1.75) and IMS content package (1.76). This result is also supported by a median and mode value of 1 for both.

- RQ2: Which Moodle features are used most frequently, and which features are used least frequently by $\mathrm{HU}$ faculty?

Table II depicts the usage analysis for Moodle features among HU instructors. Mean, median and mode were also calculated for each feature. The overall usage was represented by the mean. Hence, the features in the table were also sorted descending based on mean values. According to the table, the most frequently used feature was File (4.64), followed by Folder (3.61), Assignment (3.18) and URL (3.16). These were the most commonly used features. This result is also advocated by the median and mode values illustrated in the table. The least frequently used features were IMS content package (1.49), SCORM package (1.51), Wiki (1.57), Glossary (1.62),
Workshop (1.67), Database (1.79), Survey (1.81), External tool (1.88) and Choice (1.96).

TABLE I. FEATURES AWARENESS

\begin{tabular}{|l|l|l|l|l|}
\hline Feature & Mean & SD & Median & Mode \\
\hline File & 4.59 & 0.88 & 5 & 5 \\
\hline Folder & 3.85 & 1.26 & 4 & 5 \\
\hline Assignment & 3.62 & 1.27 & 4 & 5 \\
\hline URL & 3.56 & 1.38 & 4 & 5 \\
\hline Quiz & 3.46 & 1.39 & 4 & 5 \\
\hline Chat & 3.09 & 1.33 & 3 & 3 \\
\hline Page & 2.96 & 1.32 & 3 & 2 \\
\hline Label & 2.96 & 1.45 & 3 & 2 \\
\hline Lesson & 2.85 & 1.27 & 3 & 4 \\
\hline Forum & 2.74 & 1.36 & 3 & 3 \\
\hline Book & 2.66 & 1.18 & 3 & 3 \\
\hline Feedback & 2.63 & 1.40 & 2 & 2 \\
\hline Survey & 2.42 & 1.31 & 2 & 1 \\
\hline Choice & 2.35 & 1.34 & 2 & 1 \\
\hline External tool & 2.29 & 1.23 & 2 & 1 \\
\hline Database & 2.22 & 1.19 & 2 & 1 \\
\hline Glossary & 2.11 & 1.17 & 2 & 1 \\
\hline Workshop & 2.08 & 1.16 & 2 & 1 \\
\hline Wiki & 2.01 & 1.19 & 2 & 1 \\
\hline IMS content package & 1.76 & 1.08 & 1 & 1 \\
\hline SCORM package & 1.75 & 1.06 & 1 & 1 \\
\hline & & & & \\
\hline
\end{tabular}

TABLE II. FEATURES USAGE

\begin{tabular}{|l|l|l|l|l|}
\hline Feature & Mean & SD & Median & Mode \\
\hline File & 4.64 & 0.79 & 5 & 5 \\
\hline Folder & 3.61 & 1.30 & 4 & 5 \\
\hline Assignment & 3.18 & 1.44 & 3 & 5 \\
\hline URL & 3.16 & 1.40 & 3 & 5 \\
\hline Quiz & 2.73 & 1.44 & 2.5 & 1 \\
\hline Label & 2.69 & 1.49 & 2 & 1 \\
\hline Page & 2.66 & 1.30 & 2 & 2 \\
\hline Lesson & 2.61 & 1.41 & 2.5 & 1 \\
\hline Chat & 2.45 & 1.24 & 2 & 2 \\
\hline Book & 2.32 & 1.23 & 2 & 1 \\
\hline Forum & 2.14 & 1.25 & 2 & 1 \\
\hline Feedback & 2.07 & 1.27 & 2 & 1 \\
\hline Choice & 1.96 & 1.15 & 2 & 1 \\
\hline External tool & 1.88 & 1.08 & 2 & 1 \\
\hline Survey & 1.81 & 1.08 & 1 & 1 \\
\hline Database & 1.79 & 1.02 & 1 & 1 \\
\hline Workshop & 1.67 & 0.92 & 1 & 1 \\
\hline Glossary & 1.62 & 0.91 & 1 & 1 \\
\hline Wiki & 1.57 & 0.89 & 1 & 1 \\
\hline SCORM package & 1.51 & 0.93 & 1 & 1 \\
\hline IMS content package & 1.49 & 0.90 & 1 & 1 \\
\hline
\end{tabular}


- RQ3: Is there a statistical relationship between faculty's awareness of Moodle features and their usage?

In order to statistically answer this question, scatterplot, correlation and regression analyses were conducted.

\section{A. Scatterplot}

A scatter plot that illustrates the relationship between the overall awareness and the overall usage of Moodle features is depicted in Fig. 2. In this scatterplot, the overall awareness appears on the horizontal axis, and the overall usage appears on the vertical axis. The location of dots on the plot depends on each feature's overall awareness and overall usage.

As per the figure, the overall direction of the relationship implies a positive relationship between the awareness and usage since as the awareness increases the usage also increases. Moreover, since the dots closely resemble a straight line [29] the relationship is obviously a linear relationship. Thus, Pearson's correlation coefficient could be calculated.

\section{B. Correlation Analysis}

A correlation analysis was conducted to examine the relationship between the awareness and the usage. The correlation analysis resulted with a Pearson's correlation coefficient value of $(r=0.98)$ and a significance value of ( $\mathrm{p}-$ value $=0.00$ ). A Pearson correlation coefficient value of ( $\mathrm{r}=0.98$ ) indicates a strong positive correlation according to [30] and a very strong positive correlation according to [24] between instructors' awareness of Moodle features and their usage. A significance value of $(\mathrm{p}=0.00)$, which is less than the significance level $(\alpha=0.05)$, implies that this correlation is significant; has not come by chance and could be generalized to the entire population [31].

\section{Regression Analysis}

The conducted correlation analysis stated that there is a strong positive correlation between the instructors' awareness of features and their usage. Furthermore, to investigate how changes in the awareness are associated with changes in usage, simple linear regression test was conducted.

Regression test of the awareness as an independent variable and usage as a dependent variable resulted in a relation with $\mathrm{R}^{2}=0.95$ (see Table III) and a coefficient value of the awareness (slope) equals 1.06, see Fig. 3.

This regression analysis resulted with a $(\mathrm{p}$-value $=0.00)$ that is less than the significance level $(\alpha=0.05)$, which implies statistical significance (i.e. changes in awareness are associated with changes in the usage at the population level).

To assess the appropriateness of this linear regression model for the data, residuals analysis was conducted. A residual is the difference between the observed value and the predicted value by the model for that observation. The resulted residuals plot is depicted in Fig. 4. As residuals are scattered randomly around the x-axis and are normally distributed, then this linear regression is appropriate for the data.

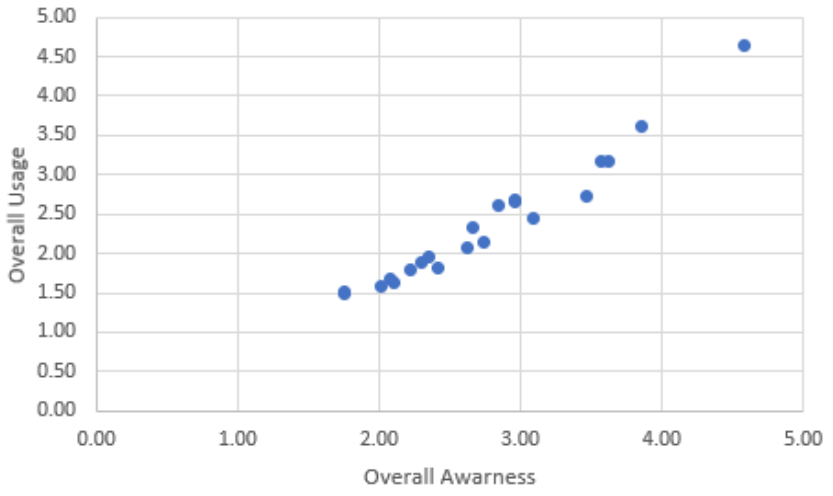

Fig. 2. Overall Awareness-usage Relationship.

TABLE III. REgRESSION STATISTICS - RESULTS

\begin{tabular}{|c|c|}
\hline Parameter & Value \\
\hline Multiple $\mathrm{R}$ & 0.98 \\
\hline R Square & 0.95 \\
\hline Adjusted R Square & 0.95 \\
\hline Standard Error & 0.18 \\
\hline Observations & 21 \\
\hline
\end{tabular}

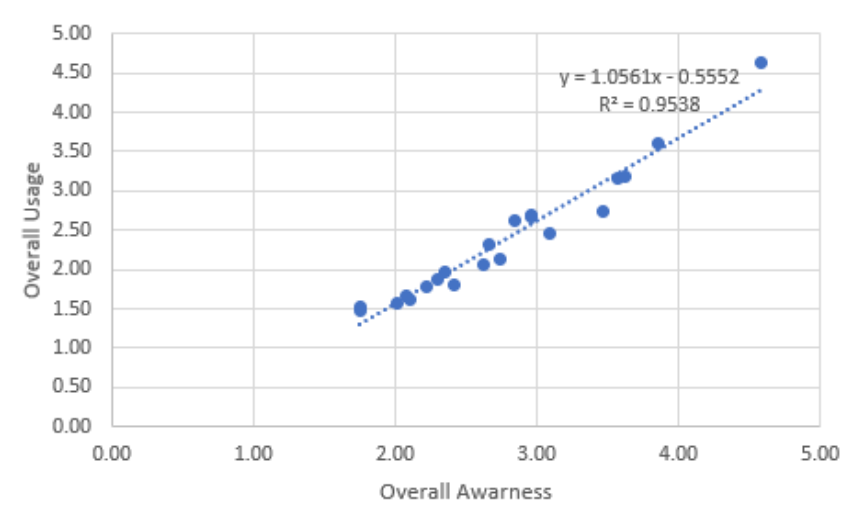

Fig. 3. Awareness-usage Regression Analysis.

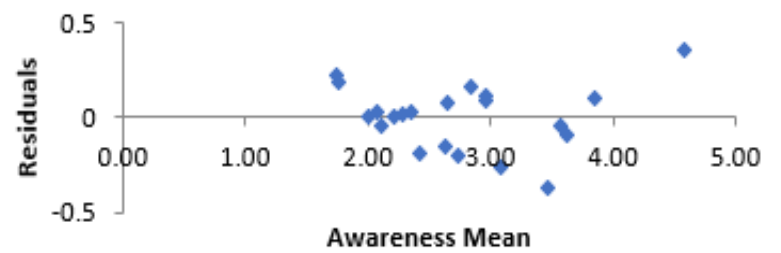

Fig. 4. Awareness mean Residuals Plot.

- RQ4: Based on (activities/resources) classification of Moodle features, which category has highest/least awareness and which category is most/least frequently used?

The awareness and usage among activities and resources were separately examined in Table IV. As per the table, HU instructors exhibited considerable higher awareness and usage $(3.19,2.94)$ towards resources than that for activities $(2.55$, 2.07). 
TABLE IV. AWARENESS AND USAGE OF ACTIVITIES AND RESOURCES

\begin{tabular}{|c|c|c|c|}
\hline & & Awareness & Usage \\
\hline Assignment & \multirow{14}{*}{ 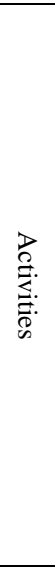 } & \multirow{14}{*}{2.55} & \multirow{14}{*}{2.07} \\
\hline Quiz & & & \\
\hline Chat & & & \\
\hline Lesson & & & \\
\hline Forum & & & \\
\hline Feedback & & & \\
\hline Survey & & & \\
\hline Choice & & & \\
\hline External Tool & & & \\
\hline Database & & & \\
\hline Glossary & & & \\
\hline Workshop & & & \\
\hline Wiki & & & \\
\hline SCORM package & & & \\
\hline File & \multirow{7}{*}{ 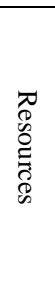 } & \multirow{7}{*}{3.19} & \multirow{7}{*}{2.94} \\
\hline Folder & & & \\
\hline URL & & & \\
\hline Page & & & \\
\hline Label & & & \\
\hline Book & & & \\
\hline IMS content package & & & \\
\hline
\end{tabular}

- RQ5: Based on the adopted functional classification of features, which categories have the highest/least awareness and which categories are the most/least frequently used?

For more convenience, awareness and usage were examined for Moodle features based on their functionalities. Table V displays the functional categories sorted by the category's awareness. HU instructors exhibited highest awareness towards "Direct Assessment" (3.54) and "Content Delivery” (3.4) features and least awareness towards “Standardized Content Package” (1.75).

TABLE V. AWARENESS OF FEATURES - GROUPED By FunCTIONALITY

\begin{tabular}{|c|c|c|c|}
\hline Category & Features & Mean & $\begin{array}{l}\text { Category } \\
\text { awareness }\end{array}$ \\
\hline \multirow{2}{*}{$\begin{array}{l}\text { Direct } \\
\text { Assessment }\end{array}$} & Assignment & 3.62 & \multirow{2}{*}{3.54} \\
\hline & Quiz & 3.46 & \\
\hline \multirow{3}{*}{ Content Delivery } & File & 4.59 & \multirow{3}{*}{3.40} \\
\hline & Page & 2.96 & \\
\hline & Book & 2.66 & \\
\hline \multirow{2}{*}{$\begin{array}{l}\text { External } \\
\text { Resources }\end{array}$} & URL & 3.56 & \multirow{2}{*}{2.93} \\
\hline & External Tool & 2.29 & \\
\hline \multirow{2}{*}{ Communication } & Chat & 3.09 & \multirow{2}{*}{2.92} \\
\hline & Forum & 2.74 & \\
\hline \multirow{3}{*}{$\begin{array}{l}\text { Indirect } \\
\text { Assessment }\end{array}$} & Feedback & 2.63 & \multirow{3}{*}{2.47} \\
\hline & Survey & 2.42 & \\
\hline & Choice & 2.35 & \\
\hline \multirow{4}{*}{ Collaboration } & Database & 2.22 & \multirow{4}{*}{2.11} \\
\hline & Glossary & 2.11 & \\
\hline & Workshop & 2.08 & \\
\hline & Wiki" activity & 2.01 & \\
\hline \multirow{2}{*}{$\begin{array}{l}\text { Standardized } \\
\text { Content Packages }\end{array}$} & IMS content package & 1.76 & \multirow{2}{*}{1.75} \\
\hline & SCORM package & 1.75 & \\
\hline
\end{tabular}

Table VI displays the functional categories sorted by the category's usage. HU instructors exhibited highest usage towards "Content Delivery" (3.21) then towards "Direct Assessment" (2.95) features and least usage towards "Standardized Content Package” (1.5), “Collaboration” (1.66) and "Indirect assessment” (1.95) features.

TABLE VI. USAGE OF FEATURES - GROUPED By FUnCTIONALITY

\begin{tabular}{|c|c|c|c|}
\hline Category & Feature & Mean & $\begin{array}{l}\begin{array}{l}\text { Category } \\
\text { usage }\end{array} \\
\end{array}$ \\
\hline \multirow{3}{*}{ Content Delivery } & File & 4.64 & \multirow{3}{*}{3.21} \\
\hline & Page & 2.66 & \\
\hline & Book & 2.32 & \\
\hline \multirow{2}{*}{ Direct Assessment } & Assignment & 3.18 & \multirow{2}{*}{2.95} \\
\hline & Quiz & 2.73 & \\
\hline \multirow{2}{*}{ External Resources } & URL & 3.16 & \multirow{2}{*}{2.52} \\
\hline & External tool & 1.88 & \\
\hline \multirow{2}{*}{ Communication } & Chat & 2.45 & \multirow{2}{*}{2.29} \\
\hline & Forum & 2.14 & \\
\hline \multirow{3}{*}{ Indirect Assessment } & Feedback & 2.07 & \multirow{3}{*}{1.95} \\
\hline & Choice & 1.96 & \\
\hline & Survey & 1.81 & \\
\hline \multirow{4}{*}{ Collaboration } & Database & 1.79 & \multirow{4}{*}{1.66} \\
\hline & Workshop & 1.67 & \\
\hline & Glossary & 1.62 & \\
\hline & Wiki & 1.57 & \\
\hline \multirow{2}{*}{$\begin{array}{l}\text { Standardized Content } \\
\text { Packages }\end{array}$} & SCORM package & 1.51 & \multirow{2}{*}{1.50} \\
\hline & IMS content package & 1.49 & \\
\hline
\end{tabular}

\section{DisCUSSION AND LiMITATIONS}

The findings of the study state that the most commonly used Moodle features at Hashemite University are File, Folder, Assignment and URL while the least commonly used features are IMS content package, SCORM package, Wiki, Glossary, Workshop, Database, Survey, External tool and Choice. Indeed, cautious comparison with similar works in the literature should be carried out as some of them investigated a subset of the standard Moodle features [4] [15], some investigated tools and features that are available in Moodle other than activities and resources [11] [13] [16], some investigated general features, criteria and tasks that could be supported by a LMS [12] [14]. Furthermore, some works targeted different population other than HEI instructors like school instructors [15], some targeted students rather than instructors [13].

Regarding awareness, it was found that HU instructors are highly aware of File, Folder, Assignment, URL and Quiz features while they are least aware of SCORM package and IMS content package.

Moreover, the study demonstrates statistically that the awareness of Moodle features and their usage are highly correlated and that changes in the awareness are associated with changes in usage. However, neither the correlation nor the 
regression implies causation [32]. In another words, statistically, it cannot be concluded that the awareness of features causes its usage, or the usage of features causes its awareness. Though, it is believed that many Moodle features are not being used that much by HU instructors due to their unawareness of them, nobody can say that awareness causes usage as other factors may exist too.

Furthermore, the study discloses that the usage and awareness of Moodle "resources" are higher than "activities". Based on their functionalities, the study also revealed that "Content Delivery" and "Direct Assessment” features are most widely used and well-known amongst HU instructors, whilst the "Standardized Content Packages" features and "Collaboration" are the least.

Generally, the results are largely consistent with the researchers' expectations.

The study might be limited by the sample size. The survey was distributed via email among the majority of HU faculty who are currently on their work. To increase number of responses, some instructors were reminded later by email and other communication facilities. A total number of 140 responses were returned. The sample represents around $22 \%$ of the HU faculty staff who are currently on their work and around 19\% of the overall faculty staff.

As the population is limited and in order to control survey distribution process, respondents were asked for their contact information in the survey. This could affect the responses, though a quick look to the responses reveals that most respondents were rational.

One more issue, the survey was opened on Feb 10, 2020 (before COVID-19 has appeared in Jordan) and closed on April 7, 2020 after around 3 weeks from being moved gradually to distance learning due to COVID-19 quarantine. This may not affect the results of this study significantly as the survey was closed in the early weeks. However, instructors' behavior towards some Moodle features may slightly differ after the end of this quarantine. This could be an interesting dimension for future work.

\section{CONCLUSION}

In this paper the awareness and usage of 21 Moodle features (activities and resources) among HU instructors have been investigated. The study has highlighted the features that have been well-known to HU instructors, these features are: File, Folder, Assignment, URL and Quiz. On the other hand, HU instructors have expressed the least awareness towards SCORM package and IMS content package features. The study also has revealed that the most frequently used features have been File, Folder, Assignment and URL while the least frequently used features have been: IMS content package, SCORM package, Wiki, Glossary, Workshop, Database, Survey, External tool and Choice. Moreover, this study has demonstrated a significant, positive, strong correlation between instructor's awareness of Moodle features and their usage. Particularly, changes in the awareness of features are significantly associated with changes in their usage.
The study also has found that Moodle resources have received higher awareness and usage than Moodle activities.

Furthermore, Moodle features have been classified based on their functionalities into seven categories, namely, Content delivery, Communication, Collaboration, External Resources, Direct assessment, Indirect Assessment and Standardized Content Packages features. Among all these functional categories, the study has indicated that "Content Delivery" and "Direct Assessment" features have been most widely used and well-known amongst HU instructors whilst the "standardized content packages" and "Collaboration features" have been the least.

At first place, this study would help responsible parties and Moodle administrators in HEIs decide about the most important features that should be installed in their customized instance of Moodle, and even any LMSs, based on the functional categories. Also, the study would help HU responsible parties in identifying the least commonly used and the least well-known features in purpose of conducting activities that aim at increasing the level of awareness and usage of Moodle features. However, conducting activities that focus on enhancing the awareness solely may help in increasing usage based on the conducted regression, but since causation is not established, this cannot be guaranteed. Further, such activities that aim at enhancing the awareness and usage of Moodle activities may reflect positively on the learning process. If such activities were conducted, another post-activity research could be conducted in the future.

\section{REFERENCES}

[1] "About Moodle," 4 Dec 2018. [Online]. Available: https://docs.moodle.org/38/en/About_Moodle. [Accessed 22 Jan 2020].

[2] R. Jeljali, L. Al Naji and K. Khazam, "A Comparison Between Moodle, Facebook, and Paper-based Assessment Tools: Students’ Perception of Preference and Effect on Performance," International Journal of Emerging Technologies in Learning, vol. 13, no. 5, pp. 86-99, 2018.

[3] "Moodle Releases," 13 Jan 2020. [Online]. Available: https://docs.moodle.org/dev/Releases. [Accessed 22 Jan 2020].

[4] D. KC, "Evaluation of Moodle Features at Kajaani University of Applied Sciences - Case Study," in Procedia Computer Science 116, 2017.

[5] "Moodle Activities," 28 Dec 2019. [Online]. Available: https://docs.moodle.org/38/en/Activities. [Accessed 22 Jan 2020].

[6] "Moodle Resources," 28 Dec 2019. [Online]. Available: https://docs.moodle.org/38/en/Resources. [Accessed 22 Jan 2020].

[7] E. Fayyoumi, S. Idwan, K. AL-Sarayreh and R. Obeidallah, "E-learning: challenges and ambitions at Hashemite University," International Journal of Innovation and Learning, vol. 17, no. 4, pp. 470-485, 2015.

[8] A. Al-Khasawneh and R. Obeidallah, "E-Learning in the Hashemite University: Success Factors for Implementation in Jordan," in Advanced Online Education and Training Technologies, IGI Global, 2019, pp. 135145.

[9] H. Mahdizadeh, H. Biemans and M. Mulder, "Determining Factors of the Use of E-learning Environments by University Teachers," Computers \& Education, vol. 51, no. 1, pp. 142-154, 2008.

[10] R. G. Jurado, T. Pettersson, A. R. Gomez and M. Scheja, "Classification of the Features in Learning Management Systems," in XVII Scientific Convention on Engineering and Architecture, Havana, 2014.

[11] V. G. Avila Jasmine , N. G. Hembra, J. M. Mueco and F. G. Zamora, "Moodle and Facebook as A Tool for Delivering Instruction and Attainment of Learning," LPU Laguna Journal of Arts and Sciences, vol. 2, no. 1, pp. 227-250, 2015. 
[12] T. M. Hamtini and H. N. Fakhouri, "Evaluation of open-source eLearning Platforms based on the Qualitative Weight and Sum Approach and Analytic Hierarchy Process," in proceedings of the 10th international conference on education ang information systems, technologies and applications, orlando, florida,USA, 2012.

[13] L. Hasan, "Investigating Students' Perceptions of Moodle LMS In Terms of Its Features and Usability," International Arab Journal of eTechnology, vol. 5, no. 3, pp. 110-122, 2019.

[14] C. Costa, H. Alvelos and L. Teixeira, "The use of Moodle e-learning platform: a study in a Portuguese University," in Procedia Technology, 2012.

[15] A. Badia, D. Martín and M. Gómez, "Teachers’ Perceptions of the Use of Moodle Activities and Their Learning Impact in Secondary Education," Technology, Knowledge and Learning, vol. 24, no. 3, p. 483-499, 2019.

[16] F. Ali, A. A. E Al-Mallah and M. Al-Sehlawi, "Exploratory study on Moodle Usage and Satisfaction Level for the Academic Faculty of CHS," in Medical Education in the GCC Countries Conference :Needs, Challenges \& Opportunities, 2013.

[17] V. Nedeva, G. Shivacheva, H. Zheleva and V. Atanasova, "Improving Cooperative Learning Activities by New Moodle Features," Applied Researches in Technics, Technologies and Education, vol. 3, no. 3, pp. 224-233, 2015.

[18] R. Purbojo, "Role of the University Lecturer in an Online Learning Environment: An Analysis of Moodle Features Utilized in a Blended Learning Strategy," in In: Persichitte K., Suparman A., Spector M. (eds) Educational Technology to Improve Quality and Access on a Global Scale. Educational Communications and Technology: Issues and Innovations., 2017.

[19] M. Piotrowski, "What is an E-Learning Platform?," in Learning Management System Technologies and Software Solutions for Online Teaching: Tools and Applications, IGI global, 2010, pp. 20-36.
[20] UMASS, "Activity Types in Moodle," [Online]. Available: https://www.umass.edu/it/support/moodle/activity-types-moodle. [Accessed 23 Jan 2020].

[21] M. Tavakol and R. Dennick, "Making sense of Cronbach’s alpha," International Journal of Medical Education, pp. 53-55, 2011.

[22] T. S. Keith, "The Use of Cronbach's AlphaWhen Developing and Reporting Research Instruments in Science Education," Research in Science Education, no. 48, p. 1273-1296, 2018.

[23] J. Chee, "Pearson's Product Moment Correlation: Sample Analysis," 2015.

[24] S. Senthilnathan, "Usefulness of Correlation Analysis," SSRN, 2019.

[25] F. Gagné, "Descriptive Statistics and Analysis in Biochemical Ecotoxicology," in Biochemical Ecotoxicology, 2014.

[26] H. J. Seltman, "Simple Linear Regression," in Experimental Design and, 2018, pp. 213-240.

[27] J. Frost, "Check Your Residual Plots to Ensure Trustworthy Regression Results!," [Online]. [Accessed June 2020].

[28] M. J. Allen, "Strategies for Direct and Indirect Assessment of Student Learning," 2008.

[29] D. S. MOORE, W. I. NOTZ and M. A. FLIGNER, "Scatterplots and Correlation," in The Basic Practice, 2013, pp. 97-123.

[30] N. Gogtay and U. Thatte, "Principles of Correlation Analysis," Journal of The Association of Physicians of India, vol. 65, pp. 78-81, 2017.

[31] D. B. F. Filho, R. Paranhos, E. C. da Rocha, M. Batista, J. A. da Silva Jr., M. L. W. D. Santos and J. G. Marino, "When is statistical significance not significant?," Brazilian political science review, vol. 7, no. 1, pp. 31-55, 2013.

[32] J. Frost, "Causation versus Correlation in Statistics," [Online]. [Accessed June 2020]. 